NP9 (continued)

Description: The treatment received by intervention schools was promotion of low-fat white milk, fruits, and vegetables. For the fall, 6 intervention (3 urban, 3 rural) and 6 control schools participated. In the spring, the control schools will become intervention schools, while fall interventions become maintenance schools.

Evaluation: Process and outcome measures were collected.

Conclusions and Implications: Most treatments were feasible to implement. Initial analysis indicates reduction in waste in treatment schools for entrees, fruit, and milk. The spring intervention is in progress.

Funding: USDA Grant \#2012-68001-19604.

\section{NP10 Factors That Enhance Application of an Ecological Approach to Preventing Childhood Obesity}

Christina Stark, MS, RD, CDN, cms11@cornell.edu, Cornell University, Division of Nutritional Sciences, Savage Hall, Ithaca, NY 14853; J. Dollahite, PhD; C. Devine, PhD, $R D$

Objective: The objective was to determine what factors influence application of an ecological approach by extension professionals.

Description: An online training course was delivered to 383 professionals, either as teams of extension/community partners or individuals.

Evaluation: Outcomes were assessed at course end and six-month follow-up using matched surveys $(n=240)$. Behavioral intentions, credential, work experience, networking utility, job scope, job support, and funding were associated with application of an ecological approach at follow-up $(\mathrm{P}<.05)$.

Conclusions and Implications: Certain personal and organizational factors can enhance professionals' ability to apply an ecological approach at the community level.

Funding: USDA Grant \#2010-85215-20665, USDA Smith-Lever and Hatch funds supported the delivery and evaluation of the online course to New York State professionals including Cornell Cooperative Extension educators.

\section{NP11 CH0ICES: A Family-Based Childhood Obesity Intervention for Low-Income Minority Children}

Cynthia Williams,PhD, williamsc@wssu.edu, WinstonSalem State University, 601 Martin Luther King Jr. Drive, Anderson Center Suite 146, Winston-Salem, NC 27110

Objective: The objective of this presentation is to discuss the effectiveness of a 6-week summer childhood obesity intervention for low-income minority children ages 10-12.

Description: Topics will include strategies and best practices for effective summer programming for youth. The target audience includes practitioners, educators, and researchers interested in childhood obesity interventions involving families and communities.

Evaluation: Project results will include a mixture of quantitative (BMI, Body Image, etc.) and qualitative (focus groups) data analysis.

Conclusions and Implications: The presentation will also include suggestions for best practices for childhood obesity interventions focusing on high-risk populations of low-income families.

Funding: USDA Grant \#2013-04365.

\section{NP12 Why Generate Rural Options for Weight Healthy Kids and Communities?}

Deborah John,PhD, deborah.john@oregonstate.edu, Oregon State University, 345 Hallie E. Ford Center, College of Public Health and Human Sciences, Corvallis, OR 97331; K. Gunter, PhD; M. Manore, PhD;

G. Langellotto, PhD; P. Hystad

Objective: A multi-level contextual model for rural obesity prevention was created and tested in Oregon to improve weight-healthy behaviors and BMI among elementary school-aged children.

Description: Measures were applied at various levels to track person-level and environmental changes.

Evaluation: Obesity is inversely associated with physical activity among 1st-6th graders, and food insecure families are less likely to provision PA opportunities for children. Rural communities, schools and families are inadequately resourced to support children's weight-healthy behaviors.

Conclusions and Implications: Improvements in the proximal food and activity context at multiple environmental levels are required to balance children's energy equation and reverse the rural obesity trend.

Funding: USDA Grant \#2011-68001-30020.

\section{NP13 Salud Para Usted Y Su Familia [Health For You and Your Family]: Childhood Obesity Prevention In Arizona, New Mexico, and Texas Border Areas \\ Joseph Sharkey,PhD, MPH, RD, jrsharkey@sph.tamhsc.edu, Texas A\&M School of Public Health, MS 1266, College Station, TX 77843-1266; J. McDonald, PhD, MS, New Mexico State University; S. Kunz, MPH, Mariposa Community Health Center; M. R. Umstattd Meyer, PhD, MCHES, Baylor University}

Objective: The long-term goal of Salud Para Usted y Su Familia [Health for You and Your Family (SPUSF)] is to reduce the incidence of overweight and obesity among Mexican-heritage children from limited- resource colonias/neighborhoods along the Arizona, New Mexico, and Texas borders with Mexico. 